Effectiveness Review Series 2018/19: Bangladesh - Management Response

\title{
Management Response
}

Oxfam Management response to the review of Resilience in Bangladesh - Impact Evaluation of the Promoting Sustainable Building in Bangladesh (PSBiB) Project.

(Effectiveness Review Series 2018/19)

[The following table should be filled out by the Country Director or his/her designee]

\begin{tabular}{|c|c|c|}
\hline Prepared by: & Dabaraj Dey, Senior Program Officer & \\
\hline Contributors: & Anisur Rahman Chowdhury-Urban Manager & \\
\hline Signed off by: & Dipankar Datta, Country Director & \\
\hline Date: & Country/Region/Campaign: & Bangladesh \\
\hline
\end{tabular}

What is the purpose of an evaluation management response (MR)?

A management response enables us to document the key learning generated from the project evaluations whilst also ensuring that the report is given careful consideration by relevant stakeholders.

The management response should:

1) Include a summary of the reflections of your team and program/project stakeholders in relation to the evaluation's findings, conclusions and recommendations;

2) Detail actions that will be taken to respond to the evaluation findings;

3) Offer an opportunity for all relevant project stakeholder to comment on the utility of the evaluation process and final report.

\section{A: Context, background and findings}

1. The context and background of the review, i.e. the purpose and scope of the evaluation.

Oxfam GB's Global Performance Framework is part of the organisation's effort to better understand and communicate its effectiveness, as well as enhance learning across the organisation. Under this

Framework, a small number of completed or mature projects are randomly selected each year for an evaluation of their impact, known as an 'Effectiveness Review'. The evaluations focus on Oxfam's global thematic key areas, namely: 'livelihood enhancement', 'women's empowerment', 'resilience', 'sustainable water' and 'good governance'. The 'Promoting Sustainable Building in Bangladesh' (PSBiB) project was selected in 2018 for an Effectiveness Review (ER) in the area of 'resilience'.

The Project:

The project aimed at reducing the negative impacts of the boom in the construction and house building industry in Bangladesh on the environment, livelihoods and communities, by enabling a transition from unsustainable Traditional Bricks (TB) to sustainable Alternative Building Blocks (AB). Drawing on the assumption that market incentives can lead to an effective and long-term transformation of the sector, the project worked to create the enabling policy environment at a national level through intensive advocacy and coalition building ${ }^{1}$, and to initiate the market by raising user and consumer awareness about the

\footnotetext{
1 This is result area 3 in the project's logical framework.
} 
benefits of $\mathrm{ABs}^{2}$, while also strengthening producers' capacity for transitioning to $\mathrm{AB}$ production and managing associated risks ${ }^{3}$ locally. The project was implemented in three pilot subdistricts:

- Sadar and Manirampur in Jessore District (rural, southwest near the Indian border); and

- Savar in Dhaka District (suburban, northwest of the capital Dhaka, central).

The project was implemented from January 2016 until June 2019 with a total budget of $€ 2,000,000$ (cofinanced by EU SWITCH Asia for $€ 1,800,000$ and Oxfam GB for $€ 200,000)$, together with three implementing partners: The Housing and Building Research Institute (HBRI), the Jagorani Chakra Foundation (JCF), and the Bangladesh Environmental Lawyers Association (BELA).

The Evaluation:

The evaluation examined the effectiveness and relevance of the PSBiB project, with a focus on policy changes and contributions to strengthening the country's resilience during the three-year period under evaluation (from January 2016 until February 2019). The evaluation thus looked at policy changes and contributions to resilience in relation to context - not at performance against logframe targets.

The objectives were three-fold:

- To generate robust evidence of the effectiveness of the PSBiB project and its contributions to observed outcomes, while also assessing its relevance for building resilience;

- To draw lessons from the piloting of a sustainable brick value chain model for designing similar resilience building projects; and

- To provide useful inputs for expanding the way Oxfam conceptualises and evaluates impact on 'resilience' at different levels (from individual to national level).

Contribution to policy change and influence towards achieving 'whole system' change cannot be assessed with the traditional counterfactual-based evaluation methods. As there is only one system, it is impossible to find valid comparisons and use statistical or experimental methods to assess the difference. A 'realist' and 'transformative' approach called PIALA (Participatory Impact Assessment and Learning Approach $)^{4}$ was used to design and implement a fit-for-purpose evaluation that assesses 'contribution to change' in relation to 'context'.

As part of the PIALA-based approach, the evaluation employed a method called Contribution Tracing to assess the project's contribution to policy change and its relevance for building national 'resilience' alongside the project's Theory of Change (ToC). Primary data was collected by conducting SemiStructured Interviews (SSIs) with key stakeholders at the national level and in the project areas in Jessore District. This was then crosschecked with the secondary data obtained from the review of project and other relevant documents. Strength of evidence and contribution were scored for each level of change in the ToC to establish confidence in the findings. Preliminary findings from this analysis were cross-validated in a brief sense-making session with Oxfam in Bangladesh and the project partners.

\footnotetext{
2 This is result area 1 in the logical framework.

${ }^{3}$ This concerns result area 2 in the logical framework.

${ }^{4}$ Cf. https://collabimpact.org/piala.
} 
Theory of Change (ToC):

For the purpose of this evaluation, the PSBiB project's Theory of Change was framed around the three interrelated 'capacities' of Oxfam's Resilience Framework (Jeans et al, 2016):

1. The transformative capacity of the institutions to achieve an effective and long-term transformation of the sector to more sustainable technologies and business practices;

2. The adaptive capacity of the brick industry to adopt sustainable technologies and business models that can prevent environmental, economic and social stresses and shocks; and

3. Its absorptive capacity to cope with stresses and shocks through inclusive supply chain linking and risk management strategies.

\section{Summary main findings and recommendations}

Bangladesh has relatively weak institutions and law enforcement, and is known for its widespread corruption and general lack of accountability in public and private sectors, all closely linked to the country's short history of violent elitist power struggles. ${ }^{5}$ In this particular context, the evaluation found that the PSBiB project's strategies and interventions have been most significant and relevant in achieving the necessary changes in policies and legislation for promoting sustainable building materials and halting the extraction of topsoil from fertile land and protected areas. These changes were conditional to building the institutional and industry's capacity to transform the sector.

Amendments to the Brick Control Act were passed by Parliament in February 2019, and amendments to the Environment Conservation Act and a new Conservation of Agricultural Land Act are expected to be approved in 2019. These changes are achieved with clear and direct contribution from the project. The new legislation prohibits unsustainable brick production and consumption and promotes the use of alternative technologies that reduce pollution and prohibit the use of agricultural topsoil. Major strides have been taken regarding the inclusion of $A B s$ in the government procurement schedules. With the new legislation coming into force during 2019, ABs will become mandatory in public sector construction works and thus more visible in smaller towns and suburban areas. This will help to create the initial market needed for producers to attract finance for investment in $A B$ technologies. The evaluation found that the project's efforts to raise awareness and develop knowledge among building experts, brick manufacturers and the wider public, have significantly contributed in building the momentum towards a sector-wide transition to ABs.

While significant and highly necessary, the project's contributions have been insufficient in triggering the market and setting the transition process in motion. The evidence suggests that this will not take place before the new legislation comes into force in the course of 2019. The government will also have to set clear transitioning targets for both the public and the private sector, as well as including the necessary guidance in the National Building Code and creating fiscal incentives to make ABs more attractive. The target setting will depend on the 'readiness' of the technologies and the manufacturers to start the supply

5 Transparency International's 2014 Corruption Perception Index ranks Bangladesh 145th out of the 174 countries and territories assessed, while World Bank's Worldwide Governance Indicators place Bangladesh in the lowest quarter of the percentile ranks (McDevitt, 2015; Rahman \& Bari, 2016). 
(i.e. adaptive capacity). The project partners were able to prepare the AB technologies and started promoting them in the project area and around the country. However, they did not succeed within the three-year period under evaluation to resolve the quality and supply chain-linking issues (i.e. absorptive capacity) that prevent manufacturers from adopting the new $A B$ technologies.

Last, the project has made important but insufficient contributions to building the transformative capacity of Bangladesh's institutions -e.g. through creating the Multi-Stakeholder Platform (MSP) that raises awareness and enables systemic learning among the different stakeholders; engaging with policy research that helps to identify the gaps and weaknesses in the existing legislation; and through public interest litigations, campaigning and media events for making the general public aware of the necessity of protecting and strengthening the country's natural resource base. Considering Bangladesh's acute and augmenting climate vulnerability; the crucial role of its agricultural land for poverty reduction and food security; the limited capacity of its institutions to protect and manage its natural resource base and strengthen the country's resilience; the project was highly relevant and made important contributions in transforming the brick industry and increasing resilience. However, these contributions were insufficient in achieving and consolidating the desired change outcomes and in establishing the mechanisms that would sustain and accelerate the transformation process after project closure. This was partly due to contextual factors (incl. the 2018 national elections) as well as research capacity issues (of the HBRI), which hampered and delayed the project's performance.

Another contributing factor was the project design. From a Sustainable Development perspective, the project would have benefitted from a more adequate time frame and a more holistic, flexible design to achieve transformative outcomes. Using a complexity-sensitive and adaptive management approach and methodology, grounded in a thorough context and power analysis, would have improved outcomes. Likewise, the project required a profound understanding of the challenges of turning a 400-year old industry with a short (localised) value chain into a long supply chain that uses modern technologies and requires advanced business capacities.

Given the country's climate vulnerability, arguably, the focus of international development support should be on strengthening the country's resilience, and in particular, the capacity of its institutions to protect and manage its land and natural resource base, rather than on reducing GHG emissions. It is tremendously important to build the transformative capacity of its institutions and the adaptive and absorptive capacity of its communities, sectors and industries to preserve, protect and strengthen the country's land and natural resource base.

Recommendations

Based on the findings and conclusions put forward in this report, the evaluation makes the following recommendations to Oxfam Bangladesh and its partners and donors:

1. Capitalise on the new legislation coming into force and the momentum built towards triggering the market by ensuring that the new legislation attracts ongoing media attention in the coming 1-2 years with national coverage. Media can play a crucial role in accelerating change. Enforcement of the new legislation will require ample media attention. Sustainable building and the use of ABs should be widely promoted by national media, making it a general people's agenda. 
2. Build a coalition of international agencies that have an interest in continuing and/or funding the work of transforming the construction and house building industry -such as the UNDP (United Nations Development Programme) and the World Bank - to mobilise resources and attract impact investments in building the absorptive and adaptive capacity of the sector. This should be integrated from a strong social and economic justice perspective. Impact investments for solving the capacity and supply chain issues and establishing demonstration sites will be needed in at least three different parts of the country. This will allow for the pilot-testing and business modelling of $A B$ production using different river soil materials. To encourage brickfield owners to shift their production to $A B s$ and to manage the risks, supply chain linking, and $A B$ extension support will be required at a suitable scale to reach a large number of producers, traders, construction workers and consumers.

3. Obtain new funding to work with BELA and the DoE (Department of Environment) on consolidating and formalising the Multi-Stakeholder Platform (MSP), with a clear plan and strategy for the next three years to ensure that (among others):

- the HBRI research on $A B$ technologies and its $A B$ material map is finalised;

- the necessary guidance is developed and included in the National Building Code;

- further amendments are made to the legislation to protect land and natural resources;

- national policy dialogues are organised on a regular basis for addressing the problems that emerge in transitioning to ABs;

- a cross-ministerial coordination and regulatory authority is created that ensures good governance of both public and private construction and infrastructure works using sustainable materials; and

- MSP activities are also taken up by the districts.

The main purpose of the MSP would be to engage all relevant stakeholders in systemic learning and identifying suitable solutions that prevent further depletion of the country's land and resources, and to collaboratively monitor and adapt these solutions whenever new environmental and social sustainability threats or issues emerge.

4. For this evaluation to elicit critical debate and reflection, we recommend the Oxfam project team and partners organise a larger stakeholder sense-making event around the findings of this report. This will hopefully lead to stakeholders enacting these recommendations as they drive the transformative change process in Bangladesh after project closure.

B: Oxfam's response to the validity and relevance of the review findings, conclusions and recommendations.

3. Overall, do the findings of the review meet with you own expectations or assessment of the project's effectiveness? Was anything identified which was surprising?

Oxfam in Bangladesh (OBD) wants to express heart-felt thanks to Adinda Van Hemelrijck for conducting this much valued evaluation. The findings and recommendations of the evaluation are significantly aligned with the findings from the project's periodic MEAL activities and the external evaluation conducted through the project. The review meets our expectations and we agree with the recommendations proposed. 
4. Any conclusions/recommendations which the country team does not agree with or will not act upon and why

There is no recommendation in the evaluation which we don't agree with but for Recommendation 3, we have accepted the recommendation with some additions. The evaluator stressed for new funding to work with BELA and the DoE on consolidating and formalising the Multi-Stakeholder Platform (MSP). We believe to formalise the "Alternative Building manufacturers and Entrepreneurs Forum" Oxfam needs to work not only with BELA and DOE but also with the other stakeholders i.e HBRI, INGOS, universities and research organizations. Oxfam also thinks that without proper market understanding this MSF will not be able to sustain for a long period. To ensure proper sustainability, private sector engagement should be the major focus.

\section{Main follow-up actions}

Oxfam in Bangladesh is committed to keep the footprint and continue the efforts to ensure a sustainable and clean brick industry in Bangladesh. All the follow-up actions are subjected on the funding situation. Meanwhile OBD is continuing a small-scale promotional work in one urban hub of Bangladesh.

6. How do you plan to use the evidence which is generated from this review? Please be as specific as possible.

The evidence and the findings articulated through this evaluation will add to Oxfam's learning in terms of promoting urban resilience. The evidence regarding the "changes in policies and regulation along with market transformation' will definitely prove useful in our ongoing interventions around building urban resilience.

7. How do you plan to apply the learning from this review to relevant or new projects in the future? Please be as specific as possible and provide context where relevant, naming projects in full where learning from the review will be applied.

The evaluation identifies this project as highly relevant and states that it made important contributions during its short period to create the conditions for a transformation of the construction and house building sector. However, it has also identified that the foundation of the project was fairly technocratic, focused on achieving rigid log frame targets that appeared unrealistic in the given political context. Such learning will be used when designing similar projects in future - projects that focus on building urban resilience and promote sustainable building materials. The idea would be to leverage the progress made through this project and build on it through a more realistic and agile results framework.

8. Is there any support your team would require in order to maximise the use of the evidence generated from this review?

Further funding is needed to continue the advocacy-based works, inclusion of financial institutions and to create new alternative brick producers in Bangladesh to achieve the Government target of making a pollution free brick manufacturing sector. 